References

Brown, G. W., Bone, M., Dalison, D. \& Wing, J. K. (1966) Schizophrenia and Social Care. Maudsley Monograph No. 17. London: Oxford University Press.

HIRsch, S. R. \& Lefr, J. P. (1975) Abnormalities in Parents of Schizophrenics. Maudsley Monograph No. 22. London: Oxford University Press.

Tarrier, N., Vauohn, G., Lader, M. H. \& Lemp, J. P. (Submitted to Nature) Bodily reactions to people and events in schizophrenics.

\section{BEHAVIOUR THERAPY}

Dear Sir,

Readers of Dr Hafner's paper (Journal, 1976, 129, p 378-83) might wonder whether the conclusions drawn come from the data presented. He states that 'About 18 per cent of patients were adversely affected by the treatment programme', . . . that 'barely two-thirds of the 39 patients benefited usefully from treatment, and the emergence of fresh symptoms was a significant problem', and 'it is inescapable that a proportion of patients who received a standard symptomatic treatment were worse one year later'.

Tables I and II in the paper show improvement in all three groups on 4 of the 5 measures given. Although we are told that at one-year follow-up Group 3 was worse on 3 out of 4 measures, excluding symptoms directly treated, these are not specified, and the tables supplied actually depict slight improvement which is probably within chance levels (MHQ $56 \cdot 8$ to $55 \cdot 3$, FSS $74 \cdot 8$ to $70 \cdot 5$, self-dissatisfaction 13.5 to $12 \cdot 1$ ); on the only measure which seemed to imply a deterioration this change was within chance limits (spouse-dissatisfaction $7 \cdot 0$ to $8 \cdot 2, P<0 \cdot 1$ ). On what criteria, therefore, were Group 3 worsened, apart from a non-significant change on a rating scale of spouse-dissatisfaction whose reliability and validity has not been presented, and despite improvement in 4 other measures? To proceed from a non-significant change on 1 out of 5 measures which is in the opposite direction to all other measures given, and then to draw conclusions about 'worsening' seems illogical.

This aside, the definition of 'symptom emergence' is questionable: 'an increase over pre-treatment scores on any scale of the MHQ of Fear Survey Schedule on more than one of the 5 post-treatment assessments.' Fluctuations in severity of agoraphobia without treatment have been so well documented that 'fresh' symptoms need to be clearly beyond the natural fluctuation. Nevertheless, patients who before treatment had rather poorer marriages exposed themselves significantly less to the phobic situation, and after treatment did less well than other patients.

I agree with Dr Hafner's point that we should seek evidence of worsening in wide areas of a patient's functions after direct treatment of a specific problem. In a study of group exposure (flooding) for agoraphobics this was done (Hand et al, 1974): marital and interpersonal relationships for a group of 25 patients as a whole improved significantly, and the gain continued at follow-up. Seven patients had to be offered help for marital difficulties; however, twothirds of the 21 married patients regarded their marriages as unsatisfactory before treatment. This emphasizes that far from treatment being responsible for making marital discord 'emerge' or become 'substituted' for phobias, improvement in phobias and obsessions spills over as improvement in other areas. In a prospective follow-up study of phobic disorders 4 years after treatment, patients who improved most in their phobias showed least subsequent depression, and the group as a whole showed no worsening of general anxiety, obsessions, depersonalization, work, social, sexual, family, or other relationships (Marks, 1971).

Briefly, Dr Hafner's data illustrate the welldocumented phenomenon that patients who improve after behavioural treatment for a main problem, tend to improve in other areas, thus negating traditional ideas about symptom substitution.

Institute of Psychiatry,

RIGHARD STERN

\section{De Crespigny Park, \\ Denmark Hill, $S E_{5} 8 A F$}

\section{References}

Hand, I., Lamontagne, Y. \& Marks, I. M. (1974) Group exposure (flooding) in vivo for agoraphobics. British Journal of Psychiatry, 124, 588-602.

Marks, I. M. (197I) Phobic disorders 4 years after treatment. British Fournal of Psychiatry, 118, 683-8.

\section{Dear Sir,}

Reading Dr Hafner's article, we are deeply concerned at the methodology employed and the lack of understanding of the principles of behaviour therapy shown by the author. We will very briefly support our criticism.

\section{Methodology}

(a) There is a lack of information concerning the treatment involved. Who took the patients into the frightening situations; was the exposure graded (gradual approach) or was the flooding technique used?

(b) The patients are divided on the basis of results arising from two questionnaires which are then transformed into a score and used for statistical analysis. It is not clear whether the increases within 